\title{
THE ELECTROENCEPHALOGRAM DURING SPONTANEOUS NIGHT SLEEP IN EPILEPTIC PATIENTS
}

\author{
Rubens MOURA Ribeiro * \\ MICHEL P. LISON * \\ J. ARMBRUST-FIGUEIREDo **
}

Recent advances in the electroencephalographic studies of normal sleep have modified the older hypothesis of the sleep mechanisms by newer interpretations, which explain sleep as the result of an inhibitory activity originating from specific hypnogenic centers ${ }^{1,7,14}$. The great importance of the sleep was stressed by Gibbs and Gibbs ${ }^{6} 20$ years ago, when these authors stated that epileptic patients show more than twice seizure discharges in their EEG recorded during sleep than in the waking state. The five well known fundamental stages of sleep with especific electroencephalographic findings were established by Dement and Kleitman ${ }^{2}$ in 1957.

These reports have presently focused the attention of the electroencephalographers upon the value of the sleep record as a useful tool for studying the electroencephalographic patterns of epileptic patients.

Our study was carried out in order to investigate the brain function of epileptic patients on the basis of electroencephalographic information during spontaneous night sleep.

\section{MATERIAL AND METHODS}

For the purposes of the present study, 5 patients with the chief complaint of convulsive disorders were investigated. The EEGs were taken first at day time as a routine procedure and have show sharp waves in the temporal leads in 4 cases, and bilateral spike and slow waves and synchronic discharges in one case. A second record was taken during spontaneous night sleep.

The EEGs were recorded on an 8 channel model VI Grass instrument, the electrodes being placed as usually in the 10/20 system; monopolar and bipolar techniques were used ${ }^{15}$. Eye movements, snoring and reactivity to auditory stimuli were also recorded.

\section{RESULTS}

The EEG findings in the 5 experiments indicate that the focal sharp waves, when recorded during the 1 st and 2nd stages of spontaneous night sleep, are characterized by a slight elevation of the frequency of the discharges. On the same way, the qualitative aspects of the bioelectrical activity of subcortical

From the Department of Neurology, Faculdade de Medicina de Ribeirāo Prêto da Universidade de São Paulo: * Assistent; ** Professor. 


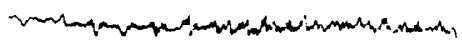

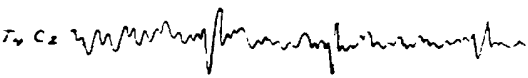

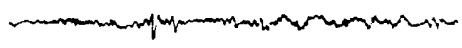

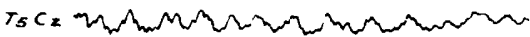

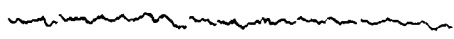

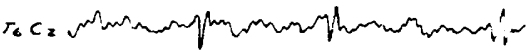

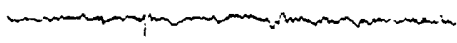

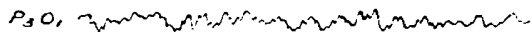

$E M$.

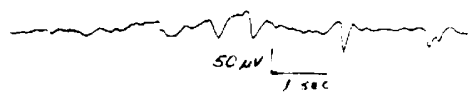

Fig. 1 - Right temporal spike waves recorded during stage II. Note some degree of changes in their morphology and amplitude during stage $J V-V$. E.M. = horizontal eye movements.

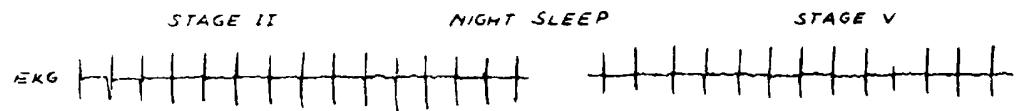

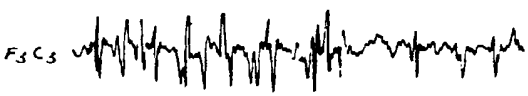

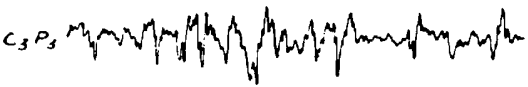

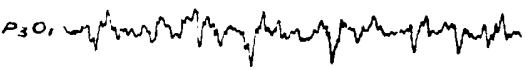

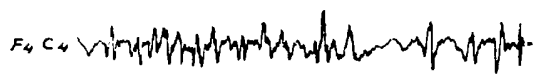

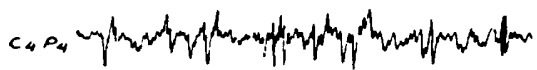

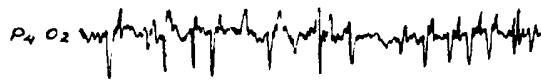

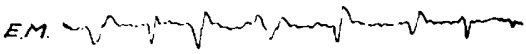

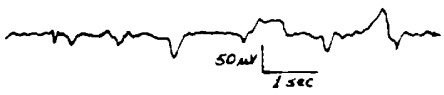

Fig. 2 - Burst of bilaterally spike and wave discharges occurring auring stage $I I$, and complete absence of the discharges during stage $V$. E.K.G. = electrocardiogram; E.M. = horizontal eye movements. 
structures, show some degree of changes in their morphology (Fig. 1). Otherwise, the patient with continuous bilateral spike and wave discharges occurring during the waking state and stages $I$ and II of spontaneous sleep, showed a complete absence of the discharges during the 5th stage or paradoxical phase of the sleep (Fig. 2) The schematic representation of the whole night sleep is shown in Fig. 3 where one can notice the differents events occurring during the record.

\section{COMMENTS}

The qualitative study of EEGs obtained during the all night spontaneous sleep has established that there are actually a stage of light sleep characterized by slow waves activity and spindles burst, and the stage of deep sleep characterized by fast activity, also known as paradoxical phase of the sleep. The experimental studies of French and Magoun ${ }^{5}$, carried out in monkeys, have demonstrated that in the first stage, also named of cortical synchronization, occurs a moderate decrease of the muscular tone in the neck muscles and a slight reduction of the blood presure. From the electroencephalographic point of view, this stage of the sleep is a very useful method of "sensibilization", mainly because it activates certain epileptic patterns, and shows some degree of reactivity for external stimulation. The second stage or deep sleep with desynchronized EEG, is characterized by vegetative disturbances, such as increase of pupil diameter and retraction of the nictante membrance of the cat. The above mentioned results suggest that the deep sleep system is related to an autonomic activity, probably of humoral nature, activating an autonomic neuro effector system elicits behavioral signs of deep sleep with desynchronized EEG patterns and eye movements ${ }^{9}$, as one can see in Fig. 3. Many authors $3,4,13$ have used the terms activated sleep and rapid eye movement phase when refering to the paradoxical phase of sleep. In this stage of sleep the EEG records show fast activity and low voltage patterns as in awaked tracings. There is a moderate decrease in paroxysmal discharges either focal or centroencephalic in origen (Fig. 1), while electroencephalographic evaked reactivity to the sensorial stimulation is still absent.

The study of both normal and pathological patterns elicited during the all night spontaneous sleep can be explained on the basis of a sleep system with localization in different levels of midbrain, which may be considered the origen of these parameters. At the present time, neurophysiological experiments related to study of all night sleep patterns suggest that the sleep system is made up of a multisynaptic pathway extending from spinal cord to the medial pontomesencephalic tegmentum. This ascending traject of hypnogenic circuit lends support to the idea that sleep is the result of an inhibitory activity exerted on subcortical level ${ }^{8}$. The reticular formation (ascending reticular activating system) at caudal pontine level represents a fundamental demonstration that different sleep patterns can be elicited by stimulation of this region. This rhomboencephalic 
center maintain correlations with the neocortex and hippocampal structures through the limbicmidbrain circuit described by Nauta. In 1960 and 1961, Jouvet et al. 11,1:2 reported that the neocortex is responsible for signs of sleep with a synchronized EEG pattern, while the rhomboencephalic region and interpenduncular nuclei seems likely to induce the deep stage of sleep with the typical desynchronized EEG patterns. In accordance to this experiments, either the light sleep or the deep sleep in cats does not need the neocortex for their manifestation.

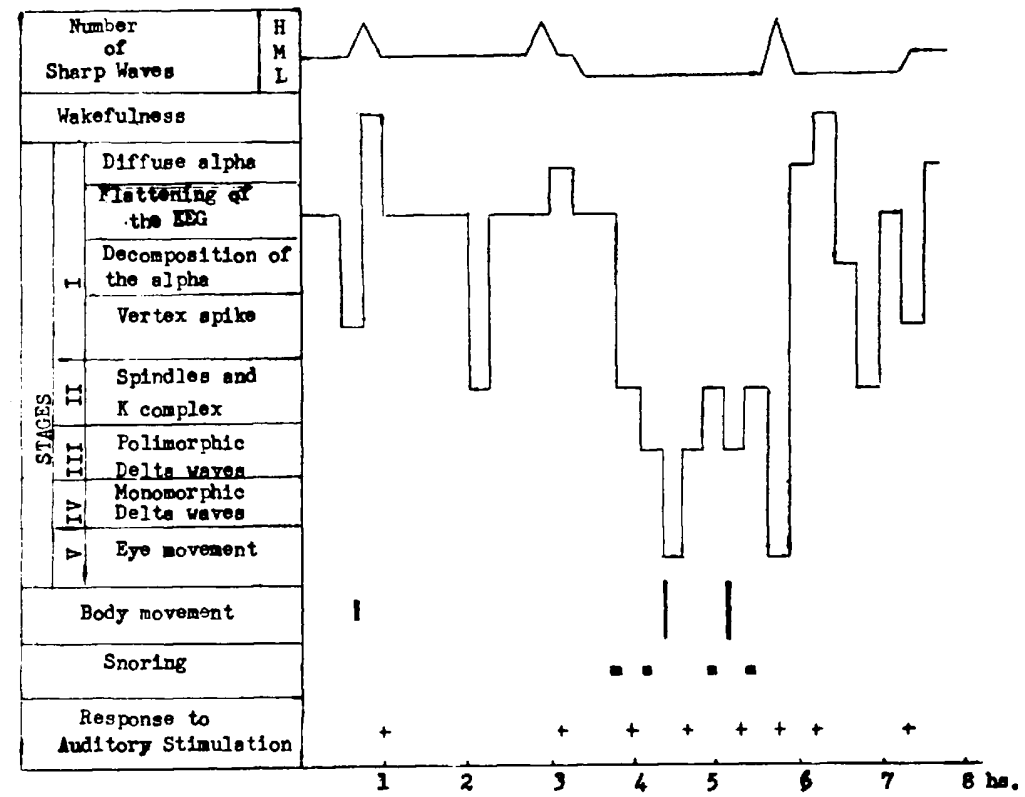

Hig. 3 - Schematic representation of the events in night sleep electroencephalogram. $H=$ high number of sharp waves; $M=$ medium number of sharp waves; $L=$ low number of sharp waves.

In spite of the neocortex being not essential for the production of sleep, experiments concerned with the effect of reticular stimulation have suggested the existence of a corticoreticular projection, which would tend to inhibit the vigilance system ${ }^{10}$. The synchronized stage of sleep represents an inhibitory phenomenon since the stimulation of reticular formation increases the level of the vigilance system.

Although our material is still very small, the recording of all night spontaneous sleep can be of practical interest on the study of epilepsy, for the sharp waves when analized in the same patient show qualitative and quantitative changes which can be correlated to the different phases of the sleep. Nevertheless the EEG is of major importance on the understanding of the electrical activity of the brain during the state of physiological sleep. 


\section{SUMMARY}

The sleep sistem results of the activity of two components: a descending component originated in the limbic structures, and an ascending system involving the bulbopontine structures which receives projections from the spinal cord components. Although the neocortex is not necessary for sleep mechanisms, it plays a very important role in sleep. Therefore, during the sleep state there is no significant quantitative difference in brain activity, but qualitative changes are recorded in EEG of epileptics patients during all night sleep.

\section{RESUMO \\ O eletrencefalograma durante o sono noturno espontâneo em pacientes epilépticos.}

Foram estudados os traçados eletrencefalográficos obtidos durante o sono noturno de 5 pacientes epilépticos. Os resultados demonstram que a atividade paroxística focal evidencia modificações tanto qualitativas como quantitativas quando registrada no $10^{\circ}$ e $2 .^{\circ}$ estágios do søno. Por outro lado, o EEG com descargas difusas e bilaterais intensas na fase inicial do sono, apresenta ausência de paroxismo na fase paradoxal. Assim, a análise dos diversos estágios do sono evidencia diferenças qualitativas e quantitativas na atividade elétrica cerebral de pacientes epilépticos durante o sono noturno.

\section{REFERENCES}

1. CLEMENT, C. D. \& STERMAN, M. B. - Cortical synchronization and. sleep patterns in acute restrained and chronic behaving cats induced by basal forebrain stimulation. Electroenceph, clin. Neurophysiol. 24:172, 1963.

2. DEMENT, W. C. \& KLEITMAN, N. - Cyclic variations in EEG during sleep and their relation to eye movements, body motility and dreaming. Electroenceph. clin. Neurophysiol. 9:673, 1957.

3. DEMENT, W. C. \& KLEITMAN, N. - The relation of eye movements during sleep to dream activity: an objective method for the study of dreaming. J. Exp. Psychol. 53:339, 1957.

4. DEMENT, W. C. - The occurrence of low voltage, fast electroencephalogram patterns during behavioral sleep in the cat. Electroenceph. clin. Neurophysiol. 10:291, 1958.

5. FRENCH, J. D. \& MAGOUN, H. W. - Effects of chronic lesions in central cephalic brain stem of monkeys. Arch. Neurol. \& Psychiat. 68:591, 1952.

6. GIBBS, E. L. \& GIBBS, F. A. - Diagnostic and localizing value of electroencephalographic studies in sleep. Res. Publ. Ass. nerv. ment. Dis. 26:366, 1946.

7. HERNANDEZ-PEON, R. - Neurophysiological mechanisms of wakefulness and sleep. Acta Neurol. Latinoamer. 10:18, 1964. 
8. HERNANDEZ-PEON, R. - Waking and sleeping patterns of brain activity and their relations to EEG. In Second advanced course in electroencephalography (L. Koisser, Vienna, 1965).

9. HODES, R. - Ocular phenomena in the two stages of sleep in the cat. Exper. Neurol. 9:36, 1964.

10. HUGELIN, A. \& BONVALLET, M. - Cortical tonus and extrapyramidal control of motricity. Electroenceph. clin. Neurophysiol. 10:343, 1958.

11. JUUVET, M.; MICHEL, F. \& MONNIER, D. - Analyse électroencéphalographique comparée du sommeil physiologique chez le chat et chez l'homme. Rev. Neurol. 103:189, 1960.

12. JouveT, M. - Telencephalic and rhomboencephalic sleep in the cat. In Ciba symposium: The nature of sleep. (G. E. W. Wolstenholme et U. O'Connor, London 1961).

13. JUUVET, M.; PELlin, B. \& MONNIER, D. - Etude polygraphique des différents phases $d u$ sommeil au cours des troubles de conscience chronique. Rev. Neurol. 105:181, 1961.

14. MONNIER, M. - Moderating and activating systems in medial thalamus and reticular formation. Electroenceph. clin. Neurophysiol. 24:97, 1963.

15. International Federation of Societies for Electroencephalography and Clinical Neurophysiology. Proc. IVth Int. Cong. Electroenceph. clin. Neurophysiol. 10: $367,1958$.

Departamento de Neurologia - Faculdade de Medicina - Caixa Postal 301 Ribeirão Prêto, SP - Brasil. 